\title{
LA EVOLUCIÓN DE LA LIBERTAD POLÍTICA EN CHILE DESDE PORTALES A BALMACEDA
}

\author{
Gonzalo Rojas Sánchez \\ Profesor de Historia del Derecho \\ Pontificia Universidad Católica de Chile
}

Mi tema es la evolución de la Libertad Política en Chile, desde Portales a Balmaceda, es decir, desde 1830 a 1891.

La cronología fundamental de nuestra Patria indica que desde el 12 de Febrero de 1818 somos una nación independiente. $Y$ aunque dentro de pocos días vamos a celebrar un aniversario que es distinto, y lo vamos a celebrar con entusiasmo, nuestra Independencia, como sabemos, es de esa fecha. Una nación independiente y libre, pero la investigación pormenorizada ha mostrado también que el camino para hacer efectiva esa libertad fue cauteloso y arduo durante gran parte del Siglo XIX.

No se trata en la exposición que a continuación haremos, de juzgar los criterios con que la libertad fue tratada desde Portales a Balmaceda, -es uno de los pecados en los que podemos incurrir los Historiadores, juzgar excesivamente desde perspectivas contemporáneas acontecimientos pasados- dije juzgar excesivamente: debemos hacer juicios, pero particularmente prudentes. Nuestra exposición está centrada en conocer más detalladamente las dificultades, las vicisitudes, con que la libertad se abrió paso, y los fundados motivos que hubo para hacerla avanzar en un contexto de orden y seguridad; libertad en un contexto de orden y seguridad.

La historia de la libertad política en el Siglo XIX en Chile es sin duda alguna la mejor demostración de cuán prudente ha de ser la exaltación de la libertad, de qué cuidadosos deben ser quienes la consagren y la expandan; de lo contrario, la amada diosa Libertad se puede asomar en toda su demoníaca potencialidad.

Ya en su famosa carta de 1822 Portales no sólo se había referido al régimen de Gobierno que buscaba para Chile, sino que además había formulado como a la pasada, -estaba escribiendo una carta no estaba escribiendo un tratado-, una primera aproximación al modo en que él entendía la libertad y las formas políticas de la libertad. Quien era entonces un comerciante y estaba en Lima, Portales, había escrito que hacía falta un Gobierno fuerte y centralizador para enderezar a todos los ciudadanos por el camino del orden y las virtudes. De modo, decía Portales, que cuando los ciudadanos se hubiesen moralizado, pudiese llegar el Gobierno completamente liberal, libre y lleno de ideales, donde tengan parte todos los ciudadanos.

Cuando se ha estudiado esta carta de Portales, la más conocida de todas sus misivas, -era un hombre de muy frecuente hábito epistolar-, el énfasis se ha puesto siem- 
pre en los aspectos más claramente autoritarios de estas palabras Portalianas: Gobierno fuerte y centralizador, moralización, pero no debe dejar de tenerse en cuenta que esa autoridad fuerte y centralizadora debería dar paso con el tiempo - Venga después el Gobierno completamente liberal, libre y lleno de ideales - a una exaltación de la libertad, de las libertades, de los ideales de participación. O sea Portales era consciente de la necesidad de fuertes restricciones temporales para enderezar a Chile y así después poder sacarlo adelante por rutas de libertad.

Es cierto que la carta que he mencionado es de 1822, que aún gobierna O'Higgins, y que solamente es una declaración de intenciones puramente teórica. Portales no tiene ninguna participación en asuntos públicos ni siquiera vive en Chile cuando escribe esa carta. Pero también es cierto que desde 1830 Portales tiene la oportunidad efectiva de llevar ese planteamiento a la práctica; han pasado apenas 8 años, y lo hará en total coincidencia con esa posición de comienzos de la década. Cuando el ahora Ministro Portales, toma en 1830 en sus manos la conducción efectiva de la República, porque en realidad él conduce la República- lo hace con la misma convicción que tenía el año 22, con la convicción de que para ordenar la situación el Gobierno debía restringir el goce de las libertades políticas, tanto en la forma como en el fondo. Tengamos en cuenta eso sí que no se trata de una restricción posterior a un largo período de ejercicio de esas libertades, porque el país estaba recién asomándose a su disfrute, a su goce, por lo tanto no es mucho lo que se perdía cuando se hablaba de restringir, pero también tengamos en cuenta que a pesar de esa incipiente vida libertaria, se hablaba mucho de las libertades, se publicaba mucho sobre las libertades, por lo que la restricción resultaba particularmente sensible a los ambientes más ilustrados.

¿Cuáles fueron las medidas que Portales tomó, -efectivamente las tomó él-, en el plano de las libertades políticas? Por una parte puso en práctica todo un conjunto de planteamientos referidos a lo que hoy llamaríamos - no se llamaba así en la época- Seguridad Interior del Estado. Planteamientos que obedecían a una clara concepción Portaliana, que aunque él no la haya formulado en un tratado, los historiadores nos hemos encargado después de plantearla orgánicamente. Portales pensaba que ese orden y esa seguridad que afectaban a las libertades, en cuyo nombre había que restringir las libertades, se basaban en personas concretas de carne y hueso y él las calificaba como los "buenos", los hombres de orden, los hombres de juicio y que piensan, los hombres de conocido juicio, de notorio amor al país y de las mejores intenciones. Al otro lado, en la otra cara de la medalla o de la moneda, Portales hablaba de los enemigos del orden, textualmente decía: "los forajidos, los lesos y bellacos", y otra cantidad de figuras; en alguna oportunidad dijo: "las putas y los cabrones" -era un hombre de un lenguaje bastante soez-; eran una cantidad de figuras a las cuales él calificaba como los "malos". Eran las personalidades que se destacaban negativamente entre la masa, una masa que él consideraba apática, floja, y a esos que se destacaban, bellacos, forajidos, a ésos tenían que estar destinadas medidas enérgicas. El propio Presidente Prieto, siguiendo estas sugerencias, este primer criterio Portaliano de distinguir entre buenos y malos, se contagió de este lenguaje y llegó a escribir, el Presidente de la República, sobre sus enemigos políticos que eran "monstruos de la anarquía, perversos ladrones, 
descarados asesinos, incendiarios, manchados con todos los crímenes conocidos, bichos indecentes y descarados". Es un lenguaje no muy presidencial.

Pero curiosamente Portales, que distinguía entre buenos y malos, pensaba que debía haber Oposición política. Pensaba que la ausencia de Oposición era muy grave para la conformación de la República a la que él, sin saberlo todavía, iba a contribuir decisivamente. Una Oposición decente, moderada y con los santos fines de encaminar a los Ministros a obrar en el sentido de la opinión y de comenzar a establecer en el país un sistema de Oposición que no sea tumultuario, indecente, anárquico, injuicioso, degradante al país y al Gobierno. O sea, los malos no, pero puede haber Oposición con tal de que no incurra en esos vicios que Portales, con ese lenguaje soez, describía. Le parecía al Ministro que la Oposición debía tener una conducta honrada y patriótica, que así mucho podía ganar el país, y ponía de ejemplo de régimen de Gobierno-Oposición, al británico. Por supuesto. Portales no dejaba de considerar que una Oposición por decente que fuese podía llevar en sí misma los gérmenes de la discordia y podía constituirse en una amenaza para la seguridad del Estado, pero aún así prefería centrar su mirada en un pocos malos proscribiéndolos, y darle oportunidad a otrós părā que se condujesen como una Oposición decente.

A los dos principios anteriores, separación entre buenos y malos, y la configuración de una Oposición decente, Portales sumaba esta idea matriz: Ninguna conspiración puede ser admitida, por eso había que proscribir a los pipiolos, había que prevenir y reprimir cualquier conspiración que pudiese estarse fraguando. Es preciso, decía el Ministro, empeñarse en prevenir y no en reparar los males; mucha prudencia acompañada con aquella dosis de dignidad y firmeza que nunca puede faltar al hombre de bien. El Gobierno, decía el Ministro, tiene que estar atento para poner remedio a un mal que sabe que existe, que se va a producir. Según Gonzalo Vial, Portales habría dicho en alguna oportunidad: "En Chile todo el mundo tiene tendencia a conspirar, hasta la Superiora de Las Carmelitas está conspirando", o sea, el hombre miraba el fenómeno conspirativo con gran preocupación, e insistía que no podía esperarse que el delito de conspiración se estuviese cometiendo y así sorprender in fraganti a los reunidos, sino que había que prevenir esas posibilidades. Ninguna conspiración podía ser admitida.

Toda esta teoría Portaliana - buenos y malos, una Oposición decente, proscripción de las conspiraciones- se fue concretando en una serie de medidas que Portales tomó en su primer Ministerio. Cuando dejó de ser Ministro se tomaron en su ausencia, pero bajo su inspiración, y se las reforzó cuando volvió en 1835 al segundo Ministerio, oportunidad en la que sabemos encontró la muerte.

Entre esas medidas, algunas llaman mucho la atención para un hombre que había escrito, Venga después el Gobierno libre, liberal, de ideales de participación. Venga... después... mientras tanto... Mientras tanto las medidas comenzaron con las bajas militares que el Ministro decretó ya en Abril de 1830. Por primera vez quienes habían sido derrotados en las escaramuzas que habían tenido lugar el año 29, algunas de ellas ya con carácter de batallas, perdieron sus empleos en el Ejército. Fueron dados de baja 
Freire y 132 oficiales. Esas bajas fueron complementadas con destierros, con prisiones, no sólo con la pérdida del empleo. Y además con un estricto control de las calles.

Ya para 1830 se había dictado un decreto sobre vigilantes, y esos vigilantes quedaban facultados para impedir toda reunión de personas en que se usen gritos sediciosos. Había que prevenir las conspiraciones, decía el Ministro, si alguien grita de manera sediciosa por la calle eso puede ir generando un clima de conspiración. Por eso cuando los vigilantes observen alguna persona o reunión de personas sospechosas que sin objeto racional se hayan detenido en las calles, están autorizados para requerirlas que prosigan su camino y se dispersen. Vamos circulando, vamos circulando. Así, decía el Ministro, se previenen frecuentísimos desórdenes que en todo tiempo se han observado en este pueblo.

A esa medida de vigilancia de las calles se sumaron las que Portales tomó respecto de la Prensa. Cerró "El Defensor de los militares Ilamados constitucionales". Cerró "El Trompeta", (qué lindo nombre para un diario: El Trompeta). Cerró "El Cura Monardes", (ya no es un nombre muy bonito para un diario). Algunos de esos periódicos los cerró acusándolos ante los tribunales respectivos, otros simplemente los tapió. En este sentido, el Ministro no se hacía problemas. Si le parecía que la prensa podía suscitar un ambiente conspiratorio, la prensa debía ser clausurada.

Las medidas se fueron complementando después de que el Ministro hubiese ya abandonado su cargo. Lo hizo el 31 de agosto del mismo año 31, alcanzó a estar un poco más de un año al frente de la política chilena, porque en realidad él estaba al frente, y como sabemos no retornó hasta septiembre del 35 al Ministerio. Pero curiosamente en esos cuatro años de su ausencia, el Gobierno del Presidente Prieto tomó medidas que iban justamente en la línea de lo que el propio Portalés había sugerido.

Se insistió en el tema de las conspiraciones y se afinó la legislación relativa a ellas, sobre todo referida a eventuales conspiraciones militares. Curiosamente las normas que el Estado de Chile aplicaba para prevenir conspiraciones militares ¡vaya Estado independiente el nuestro! eran normas contenidas en la Ordenanza del Ejército Español promulgada por Carlos III por allá por 1768, y ¿por qué?, porque seguían vigentes en Chile, y por lo tanto si un militar chileno hubiese conspirado, como algunos lo hicieron contra el Gobierno legítimo de la República de Chile, se le habrían aplicado, como efectivamente se le aplicaron, normas de la monarquía española. Eso en la década de los 30 del siglo pasado, cuando ya llevábamos por lo tanto más de quince años de independencia, desde 1818. Y les aviso, aunque no forma parte de mi exposición de hoy, que todavía en la década de los 50 bajo el Gobierno del Presidente Montt, se aplicaron en Chile sistemáticamente normas de Las Siete Partidas, o sea del Siglo XIII, a los militares sediciosos, y por lo tanto se repite el razonamiento que acabo de hacer: un Estado independiente aplica las normas de aquél del cual se ha independizado, para castigar a quienes quieren cambiar el rumbo de ese mismo Estado independiente. No a los antiguos súbditos de la monarquía española, sino a chilenos que quisieran haber cambiado por la vía de las armas el rumbo del Gobierno de Chile; ellos fueron sancionados por normas de Las Siete Partidas, de 1248. La historia del Derecho deja muchas veces con 
la boca abierta nuestras tan certeras convicciones sobre el modo en que hemos desarrollado nuestras instituciones; esas certezas se diluyen, y es bueno que se diluyan para que sean más que certezas, verdades.

Pero volvamos al tema central. $Y$ el tema central es que las conspiraciones que parecían ya comenzar a repetirse en algunos militares, debían ser sancionadas duramente, y para eso se modificaron las normas de la Ordenanza General del Ejército Español con normas propiamente chilenas que hacían muy difícil que un militar fuese sancionado con penas leves. De ese modo, se pretendía disuadir cualquier conspiración.

Pero todavía más, en 1832 el Gobierno del Presidente Prieto estableció el control de las funciones de teatro, sí, de las representaciones teatrales. Se creó una junta de tres personalidades muy ilustres, Juan Egaña, Agustín Vial, y ioh!.redoble de tambores. ¡Andrés Bello!, encargada de revisar las piezas dramáticas que hayan de exhibirse al público en esta capital de Santiago, debiendo prohibir la representación de aquellas que tiendan a turbar el orden público, a menos que estén previamente expurgadas. Ahí está la figura de don Andrés, a quienes todos tenemos en un pedestal, formando parte de una comisión de censores de funciones de teatro. Incluso más, esta comisión estaba apoyada en una serie de inspectores que deberán asistir siempre a las funciones de teatro, de a parejas, para hacer cumplir las ordenes que les diere el jefe de policía del teatro. De tal manera que si los censores hubiesen decidido que la función podía darse, pero el público se manifestase de alguna manera excesiva, los comisarios, así se les llamaba comisarios, podían suspender la sesión.

El Ministro no ejercía el cargo, pero desde Valparaíso sugería las medidas. Cuando él volvió en 1835 al Ministerio y sobre todo después de la frustrada invasión de la República por parte de Freire, su consiguiente captura, y el correspondiente juicio, y la pena de que fue objeto, Portales apretó todavía más la mano en materia de medidas. La más significativa es la que se refiere al modo en que serían castigadas las personas que habiendo sido relegadas o confinadas, fuesen encontradas en un lugar distinto del cual debiesen habitar. El que hubiere sido condenado a permanecer en determinado punto de la República o desterrado fuera de ella por sentencia judicial, por delitos de sedición, conspiración o motín, sufrirá la pena de muerte si quebrantare su condena o destierro. El Ministro no estaba dispuesto a que una aventura como la de Freire, que había sido frustrada, pudiese ser imitada por otras aventuras de otros desterrados y que tuviesen éxito. En cualquier punto de la República en que fuere aprehendido alguno de los reos comprendidos en el artículo anterior, fuera de aquél a que hubiese sido destinado, la autoridad aprehensora lo pasará por las armas dentro de veinticuatro horas sin más proceso que el necesario para comprobar la identidad de la persona y sin que de sus procedimientos se pueda interponer recurso alguno. O sea el Ministro, en 1836. mantenía los criterios del año 30 , mantenía los criterios del año 22 , en lo que a restricción de las libertades se refería.

Todavía más. Veamos la famosísima ley de facultades extraordinarias del año 37. promulgada pocos meses antes de el asesinato del Ministro. Portales le decía al Parlamento que el Presidente necesitaba facultades extraordinarias: Si no fijáis vuestra 
detenida atención en los peligros que se ciernen sobre la Patria, si no adoptáis para la extirpación de las conjuraciones el único remedio con que se puede lograr la represión de los delitos, no os extrañéis que llegue el momento de una revolución cuyos pormenores no se os refieran en el salón de vuestra sesiones ni se os transmitan por el Presidente de la República. Señores Senadores y Diputados, o le dan facultades extraordinarias al Presidente o alguno de los sublevados derribarán al Presidente y cerrarán el Congreso. Esa ley del 31 de Enero del 37 fue acompañada de la más dura de todas las disposiciones del período Portaliano, al menos en vida de Portales, los Consejos de Guerra permanentes. Esos consejos de guerra estaban destinados a reos que fuesen sorprendidos in fraganti en conspiraciones y se aplicaría a ellos las normas de la ordenanza militar, fuesen civiles o militares. Sin duda esta es la más grave de todas las disposiciones, que obedecían a ese afán portaliano suyo por encauzar a la República, sin permitir que "los carajos, los facinerosos, los cabrones, las putas" -así los llamaba- pudiesen intervenir en los asuntos públicos. El Ministro, por lo tanto en vida, hizo el énfasis no precisamente en la segunda parte de su carta del año 22, Venga después el Gobierno libre, liberal y lleno de ideales, sino más bien en la primera: Un Gobierno fuerte, centralizador, moralizante.

Pero a todo lo que hemos dicho, hay que sumar que el mayor freno a la libertad se encontraba en el control férreo que el Presidente de la República haría de ahí en adelante -no solamente en vida de Portales- de las elecciones. Tal como ha escrito con ironía Bravo Lira: El Ejecutivo le daba tanta importancia a las elecciones que no las podía dejar libradas a su suerte. Por eso obviamente las intervenía de modo directo. El sistema electoral se estructuraba en diversos planos. Por una parte el mismo Presidente de la República formaba la llamada Lista Oficial, es decir la nómina de quienes debían ocupar los cargos de Senadores y Diputados, listado que era oportunamente comunicado a los Intendentes para que estos procedieran a organizar a los electores dirigiendo sus votos hacia los candidatos oficiales, y así se practicó en las décadas del 30 , del 40 y del 50. Por otra parte, los mismos días de elecciones... Esos días parecían en muchas localidades más bien espectáculos festivos, porque para los opositores a los Gobiernos pelucones resultaba una verdadera adivinanza descubrir el lugar de funcionamiento de las mesas electorales. Algunas cambiaban de ubicación durante el día. Otras simplemente eran desconocidas y recibían los sufragios en la clandestinidad. Otras, las menos, tenían pública notoriedad, pero el acceso se veía dificultado por oportunos piquetes de mocetones. Toda esta praxis electoral se veía facilitada por las disposiciones tanto constitucionales como legales que regulaban el sufragio. Recuerden, lo saben por sus estudios de Historia del Derecho, que la Carta del 33 le otorgaba el voto a los mayores de 25 años, o en su defecto a los mayores de 21 si ya estaban casados, que supiesen leer y escribir, que tuviesen una determinada propiedad, capital, empleo u oficio, que no incurriesen en ninguna de las inhabilidades establecidas por la Constitución, y por cierto, con el perdón de la mitad de los presentes, había que ser varón. Era tan obvio, que la Constitución ni siquiera lo decía.

Estas normas, que hemos comentado, que ya de suyo son restrictivas, se veían complementadas por aquella otra, la más anecdótica de todas las normas electorales de 
la época, que establecía que sólo se podía votar si se estaba en posesión de la dichosa "Boleta de Calificación". Este papelito, este instrumento otorgado por las Municipalidades fuertemente controladas por el Ejecutivo, duraba sólo tres años, es decir alcanzaba para una elección parlamentaria; después había que renovarlo, había que pedir una nueva boleta de calificación. Era un peculiar papelito al portador, no era nominativo, por lo que podía redistribuirse entre electores afines e incluso se acumulaban varias boletas de calificación en una misma persona. Hasta 6 y 7 veces podía votar una persona, ha dicho Fernando Silva. Este curioso mecanismo redistributivo -no precisamente de los ingresos, sino de los sufragios- se practicaba con frecuencia a través de la Guardia Cívica, cuerpo paramilitar en el que participaban ciudadanos que eran efectivamente autorizados a votar una o más veces, recibían uno o más papelitos. De acuerdo al número de boletas que se les entregaban, podían votar dos, tres, hasta seis, siete veces, o simplemente eran privados de hacerlo, según la opción que hubiesen manifestado tener respecto de la inminente elección. Como se puede perfectamente imaginar el público presente, los electores eran muy pocos y estaban controlados, muy controlados. Hacia 1860 accedía teóricamente al sufragio en Chile el 1,5\% de la población.

A todo lo anterior se suman las disposiciones que establecían elecciones indirectas para Presidente de la República y Senadores, lo que facilitaba aún más el control ya que los electores de segundo grado eran todavía menos, apenas unos centenares. Las elecciones eran por lo tanto -ya que Portales había querido una Oposición decentecuasi designaciones presidenciales y recayeron durante 40 años, en el caso del principal puesto de la República, el de Presidente, en la misma persona que lo había ejercido durante un primer período. Por eso cuando se pregunta habitualmente en clases ¿Quién sucedió a Prieto? la respuesta incorrecta es Bulnes, la respuesta correcta es Prieto, ¿y a Bulnes?. Bulnes, ¿y a Montt?, Montt, ¿y a Pérez?, Pérez. Y en materia de Senadores y Diputados las mayorías gubernamentales eran tan absolutas o al menos tan amplias que con mucha frecuencia los opositores, el pipiolaje como los llamaba Portales, simplemente no presentaban candidatos usando la fórmula conocida como retractación electoral: No juego porque eres un tramposo.

¿Pero era sólo en el plano de la libertad electoral en el que con los criterios contemporáneos, encontramos fuertes restricciones a las libertades en el régimen Portaliano?, No, sin duda que no. También en otras materias directamente vinculadas con la política, con las libertades políticas, la Constitución del 33 presentaba una normativa cautelosa o directamente restrictiva. El punto más interesante es el que dice relación con los derechos políticos de reunión y asociación, que todos consideramos nucleares en la libertad política. Ninguna Constitución chilena había consagrado estos derechos hasta 1833, y no se hagan ninguna ilusión, la Constitución de ese año tampoco los consagró. Las únicas referencias a estas libertades fundamentales como son la de reunión y asociación, -las estamos practicando aquí ahora-, se encuentran en los artículos 158 al 160 y son claramente restrictivas. Como en esa época todavía no se había hecho la fácil distinción entre una reunión y una asociación, cuando los artículos mencionados 158,159 y 160 se refieren a las reuniones y hablan de reuniones de pueblo, de personas que con o sin armas desobedezcan a las autoridades, tomen el título o representación 
del pueblo, se arroguen sus derechos, hagan peticiones en su nombre, o se atribuyan derechos distintos de los expresamente conferidos por las leyes, esas referencias deben entenderse hechas a lo que hoy conocemos como una reunión, pero también a lo que hoy conocemos como una asociación.

Y en todos los casos descritos por la Constitución, las actitudes referidas en esos tres artículos eran miradas con recelo por el constituyente, con tal recelo que estaban sancionados con nulidad de derecho o incluso con las penas previstas para el delito de sedición.

Las normas que he referido estaban en plena consonancia con la reducción Portaliana de la libertad política a esa idea, también Portaliana, de una Oposición decente, de una Oposición con limitada presencia en el Parlamento, y punto. Nada de reuniones, nada de asociaciones políticas. Los grupos extraparlamentarios, permanentes o circunstanciales, serán sistemáticamente calificados en las décadas del 30, del 40, del 50, como infectados por un espíritu pernicioso, el espíritu de partido. Un vicio terrible que se consideraba propio de los hombres que buscaban dividir a la República -partido, partir, dividir- y tenían buenas razones los constituyentes del 33 y sus inmediatos sucesores para mirar así a esos grupos, considerando la situación que Chile había vivido entre la caída de O'Higgins y el comienzo de la era Portaliana, no era la suya una idea caprichosa.

Esta misma desconfianza frente a las posibles manifestaciones políticas inadecuadas, llevó al redactor de la Constitución del 33 a entregarle, más encima, una serie de facultades excepcionales al Presidente de la República; como si fuera poco todo lo anterior -control electoral, carencia de derechos de reunión y asociación más todas las medidas en el plano legal y reglamentario que Portales fue tomando- la Constitución le entregaba al Presidente la Declaración de Estado de Sitio, con ciertos requisitos, respecto del cual quizás Uds. recordarán que la Constitución afirmaba que una vez declarado se suspendía el imperio de la Constitución. Es decir, que casi todas las libertades quedaban a merced del Poder Ejecutivo. A esa atribución tan amplia se sumaba la eventual utilización de la transferencia de facultades extraordinarias que el Parlamento podía trasladarle al Presidente, y ese traslado implicaba que el Presidente podía suspender o restringir por lapsos determinados algunas libertades específicas. Durante el Estado de Sitio, todas. El carácter excepcional de las medidas que he descrito, Estado de Sitio y facultades excepcionales, fue haciéndose paulatinamente muy frecuente, nada excepcional, hasta el punto que durante los tres primeros decenios, más de un tercio del tiempo de los Presidentes Prieto, Bulnes y Montt, el país lo vivió bajo régimen de Estado de Sitio, bajo régimen de facultades extraordinarias o bajo ambos.

Bien puede comprenderse que a esas alturas no era Portales ya, muerto en 1837 , sino que eran quienes interpretaban su voluntad, los que mantenían bajo estricto control a la Oposición política. Pero también es cierto que ya en la fase inicial, en los primeros años de la administración Bulnes, entre 1841-1846, se vivió en Chile una primera etapa de apertura política, que aunque no se concretó en una reforma de la Constitución o en la consagración a nivel legal de nuevas garantías prácticas respecto de los 
derechos políticos, implicó un clima de mayor tolerancia y participación; sólo un clima, no una consagración constitucional ni reformas legales; pero al menos un clima. Hasta el mismo Diego Barros Arana, escribiendo Un Decenio en la Historia de Chile referido a la presidencia de Bulnes, sostiene que fueron años de apertura política por parte del Gobierno. Fue en esos años 41, a comienzos del 46, que los antiguos pipiolos pudieron por vez primera darse a conocer como liberales, se libraron del estigma de los malos que sobre ellos había recaído en la década anterior.

Aunque a partir del año 46 los liberales sintieron traicionada la confianza que habían depositado en el Presidente Bulnes, debe destacarse que ya habían logrado una primera inserción en la vida política práctica que con el paso de las décadas sería irreversible. ¿Por qué este clima de apertura cambió desde el año 46? ¿Qué pasó en la segunda administración Bulnes como para que las libertades políticas no siguiesen desarrollándose? ¿No era ya la época en que ... Venga después el Gobierno libre, liberal, lleno de ideales de participación? ¿Qué pasó? La respuesta está en el surgimiento de las primeras invocaciones hechas por alguna prensa a la acción política de los artesanos, es decir de los trabajadores manuales, porque así se les denominaba en esa época. Esta llamada a los trabajadores manuales a participar en política, remeció profundamente la mirada tolerante con que los sucesores de Portales parecían estar considerando las primeras formas de Oposición política. En Marzo del 46, Montt, Don Manuel, Ministro del Interior de Bulnes, estimó que esos llamados que la prensa hacía a los obreros a participar en política (es cierto que algunos de esos llamados eran particularmente sediciosos) podían traer graves consecuencias para la tranquilidad de la República, por lo que le recomendó al Presidente Bulnes que dictara el primer Estado de Sitio a lo largo de toda su administración -habían pasado 5 años sin Estado de Sitio- y esa tesis fue apoyada con entusiasmo por los jóvenes pelucones (ya más bien habría que decir conservadores) integrados en la sociedad del orden. El propio Presidente, con reticencia, acogió la sugerencia de Montt y tuvimos Estado de Sitio. Se terminaba la apertura, la luna de miel, volvían las desconfianzas, por cierto con fundamentos bien probados, ya que los llamados subversivos por la prensa se habían difundido ampliamente y no eran en absoluto tenues, pero se iniciaba así un largo período de confrontación por las libertades políticas que no terminaría sino con el final de la administración del propio Manuel Montt.

Quince años. 1846 -1861, fueron quince años en los que el país vivió en paralelo el más interesante proceso de confrontación entre una concepción del orden y una concepción de la libertad. El mismo Montt tenía por lema "Orden y Progreso". Para él el orden era la condición fundamental del progreso y ya mucho antes de que llegara a la Presidencia de la República se notó claramente que prefería el orden como condición fundamental, puesto que la incidencia que Montt había tenido en las políticas de la segunda parte de la administración Bulnes había sido decisiva a favor del orden, restringiendo la libertad. Lo había hecho directamente, lo había hecho también a través de Antonio Varas, y sus criterios respecto de los enormes riesgos que implicaba una libertad política ilimitada se habían hecho sentir en un Bulnes que era mucho más proclive a la libertad. El héroe de Yungay estaba mucho más dispuesto a dejar atrás las restric- 
ciones Portalianas, pero tuvo que ceder ante la evidencia que Montt y Varas le presentaban respecto de una Oposición que se hacía más beligerante y rupturista.

El punto clave estuvo en el apasionante surgimiento de la Sociedad de la Igualdad, en 1850. Ese fue el caso de laboratorio, perfecto, adecuado, para medir la reacción de los Portalianos frente al fenómeno de la libertad política. Yo no sé como habría reaccionado Portales en 1850 (trece años llevaba ya en su tumba; nadie puede saberlo) pero sí puedo asegurarles que lo que hicieron Montt y Varas ese año -abiertamente Varas que era el Ministro del Interior de Bulnes- correspondió al modo en que Portales actuaba veinte años atrás, o sea Montt y Varas estimaron adecuado mantener en 1850 los criterios de seguridad nacional, que su mentor Portales tenía por allá por 1830. todavía más atrás, en 1822. La Sociedad de la Igualdad fue ciertamente una amenaza al proceso iniciado por Portales en 1830, y tanto Montt como Varas privilegiaron el concepto de orden amenazado por la Sociedad de la Igualdad, un orden que veían como la piedra angular del proceso Portaliano, por encima de todo avance de la libertad o, más bien, dándole marco a cualquier avance de la libertad. La Sociedad fundada por Bilbao, Arcos, Vicuña Mackenna, Lillo, Carrera hijo, aunque no era la sociedad de la libertad, llevaba un nombre relativo a uno de los otros dos grandes principios revolucionarios, igualdad; pero era evidente que la Sociedad tanto por sus organizadores como por el objetivo que se proponía, afectaba seriamente la concepción Monttista de la libertad. Las reacciones contra la Sociedad no se hicieron esperar. Poco a poco, desde la Intendencia de Santiago, los hombres de Bilbao y de Arcos se vieron afectados por las más estrictas restricciones, como si estuviéramos por allá por el año 30 . Se les prohibió salir en cuerpo a la calle una vez terminadas las sesiones privadas de la Sociedad. Se les atacó con mocetones en sus propios locales, jles dieron cada paliza! y finalmente la Sociedad de la lgualdad fue disuelta por considerársela atentatoria al orden establecido. La imagen muy reciente de los clubs franceses de la revolución del 48, que había traído además el triste recuerdo de los jacobinos de 1793, sí, el triste recuerdo de Robespierre, esa imagen afectó negativamente a la Sociedad de la Igualdad, y justificó que desde el Gobierno se les hiciera a todos los sectores opositores una severa advertencia en contra de todo tipo de sociedades y de clubs. En 1851 han pasado ya veinte años desde el comienzo de la acción Portaliana, pero aún se sigue pensando que la Oposición se debe canalizar sólo por la vía parlamentaria (y ya sabemos cuán controladas están las elecciones) y nunca de modo marginal al funcionamiento del Congreso, como sí se lo había propuesto la Sociedad de la Igualdad. Sin duda alguna lo que sucedió con Bilbao y su gente fue un síntoma claro de la confluencia en el Chile de esos años de dos concepciones sobre la libertad política: la que Montt y Varas seguían defendiendo estrictamente, dependiente del orden publico y de la seguridad del Estado, y la que los igualitarios propiciaban de modo enérgico, frontal, muy romántico, con el respaldo tácito de un liberalismo más moderado. Con la restricción que se decretó a la sociabilidad política formal que implicó la clausura de la Sociedad, insisto, y la prohibición de otros clubs políticos, la Oposición veía cerrarse los espacios de libertad que había ganado ¿Cuándo los había ganado? En la primera administración Bulnes, y ahora al terminar la segunda administración del mismo presidente la Oposición se encontraba sin aire. 
Esa terrible impresión de ahogo les parecía corroborada con la inminente candidatura Montt a la Presidencia de la República. Por eso simplemente los opositores optaron por la revolución, en una búsqueda tan frenética como errónea de la ansiada libertad. Con el Presidente Montt recién electo una guerra civil fue una pésima partida, una malísima partida, pero lo fue aún peor para el desarrollo de las libertades publicas en Chile, avance que por causa opositora parecía no justificarse todavía. Si Bilbao en estos años, con su lenguaje peculiar, su pelo ensortijado, sus ojos en espiral, comenzaba a llamar tirano, dictador, a Montt, Montt tenía buenas razones después de oír lo que Bilbao le decía para proscribirlo, para vigilar atentamente sus movimientos, para considerarlo un peligro para el orden. Pero cuidado, el Presidente Montt buscaba mucho más que implantar una política represiva. De ahí su afán por tratar de consolidar el progreso dentro del orden. Montt sabía que la búsqueda de la libertad fuera del orden terminaría por deshacer dos décadas de enormes esfuerzos sistemáticos de lo que después se ha llamado la República en forma, pero en su grandeza el joven Presidente comprendía que no podía mantener para siempre al margen de la vida política los sectores liberales, por errónea que hubiese sido su actitud de ir a las armas. A esos sectores liberales que exigían un espacio tantas veces negado, había que abrirles un camino. Por eso el afán de Montt, permanente, un afán que desgraciadamente sectores conservadores más estrictos le moderaron, su afán permanente de consolidar políticas de amnistía en la década de los 50 , de amnistiar una y otra vez de manera cada vez más amplia los delitos de la Oposición. Esos mismos delitos que eran sancionados con normas de Las Siete Partidas eran objeto de frecuentes y más amplias amnistías. Para Montt la amnistía era una forma de rehacer la Patria, de rehacer además dentro de ella el tejido de las libertades tan dañado. Montt no cesó en esta convicción a pesar de que debió enfrentar, como todos sabemos, una segunda guerra civil en 1859. Pero este nuevo conflicto convenció al Presidente de que las coordenadas Portalianas de seguridad del Estado ya no eran viables, y Chile se quedó sin Varas, pero Chile comenzó a consolidar un segundo intento por abrir el espacio de las libertades públicas. Si Montt se hubiese empeñado en Varas... pero entendió que no había posibilidad de consolidar lo avanzado. ya casi treinta años de progreso, sin abrir legítimamente un espacio a quienes por dos veces no lo habían encontrado y habían recurrido, para ganárselo, a las armas. No fue la guerra civil en cuanto ganasen los opositores lo que determinó a Montt, porque perdieron. Montt resultó dos veces triunfador. Fue la convicción del mismo Presidente en el sentido de que si por dos veces los opositores habían recurrido a las armas en su contra, bien podría haber una tercera y una cuarta, contra Varas. El sistema tenía entonces que ofrecer una posibilidad efectiva de participación, y si por otra parte los opositores de hecho venían ejerciendo algunas libertades políticas en el Parlamento, porque tenían representación parlamentaria, si además las doctrinas políticas cada vez eran más extensamente insistentes en la necesidad de consolidar la libertad, el Presidente Montt encontró el clima necesario para allanarse a esta inserción de la libertad en el orden.

El nacimiento de hecho de los primeros Partidos políticos chilenos, conservadores, radicales, liberales, nacionales, todos fundados a finales de los 50 , comienzos de los 60 , dio efectivamente el sustrato para que las prácticas de libertad política llegaran a consagrarse más adelante en reformas constitucionales. Los grupos parlamentarios se 
habían venido distinguiendo más unos de otros, configúrandose en la década de los 50 como los gérmenes de los futuros Partidos; Partidos no autorizados por la Constitución, Partidos no respaldados por el derecho de asociación, pero al fin de cuenta, Partidos. Las prácticas que estos grupos realizaban en el Parlamento, por ejemplo su recurrente costumbre de citar a los Ministros para interpelarlos, su afán de retener la discusión de las leyes periódicas y en particular la de Presupuesto, todo esto había ido distinguiendo grupos. La praxis política había ido reconociendo el ejercicio de una libertad de asociación no consagrada por la Constitución.

Por supuesto la tantas veces mentada ruptura del tronco pelucón, a raíz de la mucho más veces mencionada cuestión del sacristán, así como la guerra civil del 59 , terminaron por definir cuatro grandes grupos políticos de hecho, sin respaldo constitucional ni legal. Cuatro agrupaciones con aproximaciones diversas a la libertad y al orden, cuatro agrupaciones que hicieron uso de la libertad, aunque fuese de hecho para defender o más la libertad o más el orden. Por eso, no es extraño que con la presidencia Pérez comience el predominio de los Partidos, que tenía un objetivo fundamental: que reinase la libertad electoral. Ya durante Pérez los Partidos conforman con el Presidente las listas de las candidaturas y abren la vida electoral a una mayor libertad. Es cierto que el carácter de Pérez no es particularmente enérgico, que nos es precisamente Montt ni Varas, pero también es cierto que son los Partidos los que van poco a poco consiguiendo un espacio que primero han copado en el Parlamento y que ahora están trasladando al modo de generar el Parlamento, es decir a las elecciones. Pero la Constitución sigue siendo restrictiva; de ahí los Clubs de la Reforma, de ahí el surgimiento de un auténtico afán de reforma constitucional, porque hay que plasmar en la Constitución lo que las prácticas ya reconocen, una libertad política creciente que busca liberarse de la tutela presidencial. El Presidente de la República va siendo percibido como el gran enemigo de las libertades y en el caso de Pérez no hay ninguna intención de permanecer en esa postura. Ahora, además, con un gobierno de fusión liberalconservadora están dadas las condiciones, con los nacionales o Montt Varistas fuera del poder para hacer profundas reformas constitucionales. Y esas llegarán en el gobierno de Errázuriz Zañartu. Esas reformas, las primeras reformas hechas a la Constitución casi cuarenta años después de su promulgación (¡caramba como había resistido el texto!, ¡caramba la confianza que había en el texto como gestor de políticas de orden!) apuntan todas a consagrar mayores espacios de libertad.

El nuevo sistema electoral -con esa curiosidad tan notable del voto acumulativo, es decir, poder sufragar varias veces por una misma persona de tal manera de privilegiar las minorías, con las restricciones al Estado de Sitio que se impusieron, limitando el Estado de Sitio en el tiempo y limitando las garantías que el Presidente podía suspender o restringir, o lo que es más importante todavía, la efectiva consagración por primera vez en la historia de la República de los derechos de reunión y de asociación- apuntaba a colocar en el texto constitucional ese espacio de consagración fáctica de la libertades políticas que se había ido consolidando después de Pérez, no derrotando a Montt sino precisamente porque Montt había tenido la suficiente sapiencia para darse cuenta que ya no era tiempo para que el orden ahogase las libertades. 
¿Sería esto lo que Portales quería cuando por allá por el año 22 decía: Venga después el Gobierno, libre, liberal? Es posible que sí, en cuanto a los contenidos de las libertades, pero probablemente no en cuanto al espíritu, en el sentido que estas libertades fueron acompañadas de un protagonismo del Parlamento en detrimento del poder presidencial. Es probable que Portales hubiese visto con agrado la consagración de libertades políticas ya en los años 60 y 70 pero también es probable que hubiese visto con profundo rechazo la preeminencia que el Parlamento comenzaba a tomar en el ejercicio de esas libertades y en detrimento del poder presidencial. Es probable que hubiese visto el énfasis puesto por los Partidos en la libertad electoral como un nuevo peligro para el orden de la República, y que el control que los Partidos tomaban ahora de las elecciones, lo hubiese considerado tan grave como las conspiraciones de los 30. Quizás Portales habría rechazado profundamente las prácticas parlamentarias de interpelación de Ministros, de retención de leyes periódicas; porque eran unas libertades que comenzaban a plasmarse de un modo oligárquico. ¡Qué paradoja! justamente las mismas libertades por las cuales radicales, liberales y conservadores, habían luchado contra los nacionales o Montt-Varistas, no se hacían extensivas a amplias mayorías, sino más bien quedaban reducidas a oligárquicas minorías. No era ese, casi con toda seguridad, el Venga después el Gobierno libre, liberal.

Por eso, la figura de Balmaceda, que debe ser considerada a la luz del desarrollo de las libertades parlamentarias ya mucho antes del así llamado parlamentarismo, debe ser contrastada no con las libertades que se ejercían en el Parlamento, sino con el hecho de que esas libertades se ejerciesen por parte de un grupo muy minoritario que se satisfacía con practicarlas en el Congreso, sin trasladarlas al conjunto de la sociedad chilena. Balmaceda quiso recuperar la fuerza presidencial para tratar de conducir las libertades que los grupos le habían arrebatado al Presidente y se habían dejado para sí, para tratar de conducir las libertades en un contexto de nueva fuerza presidencial hacia el conjunto del pueblo de Chile. De ahí esa imagen que el pueblo de Chile tuvo de Balmaceda como un hombre de los suyos, un hombre que atacó a la oligarquía. Es cierto que quiso recolocar las libertades bajo control presidencial, pero también es cierto que las libertades habían salido del control presidencial para quedar en manos de un control oligárquico, y que Balmaceda quiso enfrentar esa hegemonía oligárquica para poder distribuir mejor las libertades. Los Partidos se han hecho, en los días previos a la guerra civil, maquinarias de administración de las libertades publicas, y Balmaceda pretendiendo ser un nuevo Montt, cuarenta años después del Montt que comenzara en 1851 a frenar las desviaciones de la libertad no leyó bien la dificultad que tenía enfrentarse a la oligarquía que administraba las libertades. Por eso el triunfo en la guerra civil del 91 parece el triunfo de las libertades frente a la opresora actitud de un Presidente dictatorial. Dictador le dijo el Parlamento a Balmaceda, pero en realidad no es más que la consolidación de un conjunto de libertades que la oligarquía ha tomado para sí y que administrará durante más de treinta años, durante el lamentable régimen parlamentario.

El parlamentarismo es la trágica consecuencia de un énfasis puesto por los Partidos en las libertades para sí, y es también la trágica consecuencia de un Balmaceda 
Revista de Derecho - U. Católica del Norte - Campus Guayacán - 2000

que no pudo ni supo encontrar el modo de recuperar para el pueblo de Chile, no para el Presidente de la República, las libertades ahora de monopolio oligárquico.

Por eso estimados Profesores, queridos alumnos, y estas son mis palabras finales, criticar la lentitud, la parcialidad con que las libertades se fueron configurando en el Siglo XIX, parece sólo la mitad del juicio que debemos hacer, porque cuando esas libertades entraron en un proceso de aceleración en el marco de la oligarquía, nos condujeron al más espantoso baño de sangre que ha vivido la República. Miremos también esa lentitud, esa parcialidad con que las libertades se fueron desarrollando, sobre todo en los primeros treinta años, como un síntoma de la prudencia que ya a partir de los años sesenta se perdió, como un síntoma de la prudencia con que ellas fueron administradas, de tal manera que se las pudiese compatibilizar con el orden. Cuando la oligarquía fue capaz de pasar con las libertades por encima del orden, el país pagó el precio -no lo pagó la oligarquía- de 10.000 muertos.

En esas condiciones yo prefiero el orden, aunque sea restrictivo de las libertades.

Muchas gracias. 